\title{
Successful treatment of optic neuropathy in association with systemic lupus erythematosus using intravenous cyclophosphamide
}

James T Rosenbaum, Jennifer Simpson, C Michael Neuwelt

\begin{abstract}
Background-Optic neuropathy is a rare manifestation of systemic lupus erythematosus (SLE). In a previous series most patients with optic neuropathy in association with SLE had a final visual acuity of 20/200 or less despite corticosteroid therapy.

Methods-Three patients (five affected eyes) with severe retrobulbar optic neuropathy in association with SLE were treated promptly with intravenous cyclophosphamide and corticosteroids.

Results-All patients recovered excellent visual acuity.

Conclusion-Although optic neuropathy in association with SLE might have several different aetiologies, intravenous cyclophosphamide should be strongly considered as a therapeutic alternative. (Br f Ophthalmol 1997;81:130-132)
\end{abstract}

Optic neuropathy has many causes including a demyelinating disease, ischaemia, sarcoidosis, systemic lupus erythematosus (SLE), Behçet's disease, vasculitis, and several infections including syphilis, Lyme disease, and cat scratch fever. Multiple sclerosis is easily the most common systemic disease associated with optic neuritis. ${ }^{1}$ High dose intravenous corticosteroid for patients with optic neuritis and no apparent systemic disease is beneficial with regard to visual acuity and in reducing the onset of clinical multiple sclerosis within 2 years of this treatment. $^{2}$

The use of corticosteroids in the treatment of optic neuropathy in association with SLE has been disappointing. In reporting their

Table 1 Patient characteristics experience with seven patients with optic neuropathy in association with SLE, Jabs and colleagues noted that 13 of 24 patients with SLE as described in their series and others had final visual acuities of $20 / 200$ or worse. ${ }^{3}$

One of us (CMN) has recently reported a favourable clinical experience with the use of intravenous cyclophosphamide for the treatment of severe central nervous system manifestations of SLE. ${ }^{4}$ We now report more detailed observations with regard to the optic neuropathy in two of the patients from that original series as well as a third previously unreported patient.

Patients, methods, and results

Two patients have been reported previously by one of us (CMN), but no information with regard to visual acuity was provided. The third patient was evaluated at the uveitis clinic of the Casey Eye Institute, Oregon Health Sciences University, Portland, Oregon.

Characteristics of the patients are summarised in Table 1. All patients were female. All patients clearly satisfied the American College of Rheumatology diagnostic criteria for SLE. ${ }^{5}$ All patients had a strongly positive antinuclear antibody test. In all patients the diagnosis of SLE had been established before the onset of the optic neuropathy. Two of the patients had other central nervous system manifestations of systemic lupus. Each patient had what clinically appeared to be retrobulbar optic neuritis with a normal appearing optic nerve and fundus. The patients with unilateral or asymmetric disease displayed an afferent pupillary defect. Each of the patients was treated with intravenous cyclophosphamide within 2 weeks of the onset of the visual loss. Each patient regained near normal visual acuity but the
Oregon Health

Sciences University,

Casey Eye Institute,

Portland, Oregon,

USA

J T Rosenbaum

J Simpson

C M Neuwelt

Correspondence to: J T Rosenbaum, MD, Oregon Health Sciences

University, Casey Eye Institute, $3375 \mathrm{SW}$

Terwilliger Blvd, Portland, OR 97201, USA.

Accepted for publication 14 October 1996

\begin{tabular}{|c|c|c|c|c|c|c|c|}
\hline Patient & $\begin{array}{l}\text { Age at clinical } \\
\text { onset of SLE } \\
\text { (years) }\end{array}$ & $\begin{array}{l}\text { Age at onset } \\
\text { of optic } \\
\text { neuritis } \\
\text { (years) }\end{array}$ & Initial VA & $\begin{array}{l}\text { Length of } \\
\text { follow up } \\
\text { (months) }\end{array}$ & Final VA & Treatment & Other SLE features \\
\hline FS & 42 & 53 & $\begin{array}{l}\text { RE: NLP } \\
\text { LE: LP }\end{array}$ & 24 & $\begin{array}{l}\text { RE: } 20 / 25 \\
\text { LE: } 20 / 30\end{array}$ & $\begin{array}{l}\text { Cyclophosphamide iv, } \\
\text { prednisone orally, } \\
\text { methylprednisolone iv }\end{array}$ & $\begin{array}{l}\text { Arthritis, nephritis, } \\
\text { pleuritis, alopecia, } \\
\text { possible } \\
\text { pneumonitis }\end{array}$ \\
\hline YJ & 25 & 32 & $\begin{array}{l}\text { RE: } 20 / 20 \\
\text { LE: HM }\end{array}$ & 50 & $\begin{array}{l}\text { RE: } 20 / 25 \\
\text { LE: } 20 / 20\end{array}$ & $\begin{array}{l}\text { Cyclophosphamide iv } \\
\times 2\end{array}$ & $\begin{array}{l}\text { Myelopathy, } \\
\text { peripheral } \\
\text { neuropathy, } \\
\text { seizures, } \\
\text { pleuropericarditis, } \\
\text { arthritis }\end{array}$ \\
\hline FB & 53 & 56 & $\begin{array}{l}\text { RE: LP } \\
\text { LE: } 20 / 20\end{array}$ & 69 & $\begin{array}{l}\text { RE: } 20 / 30 \\
\text { LE: } 20 / 20\end{array}$ & $\begin{array}{l}\text { Cyclophosphamide iv } \\
\times 2 \text {, prednisone orally }\end{array}$ & $\begin{array}{l}\text { Seizures, } \\
\text { mononeuritis } \\
\text { multiplex, } \\
\text { polyarthritis, } \\
\text { proteinuria/casts }\end{array}$ \\
\hline
\end{tabular}

$\mathrm{RE}=$ right eye $\mathrm{LE}=$ left eye $\mathrm{NLP}=$ no light perception; $\mathrm{LP}=$ light perception; $\mathrm{HM}=$ hand movements. 


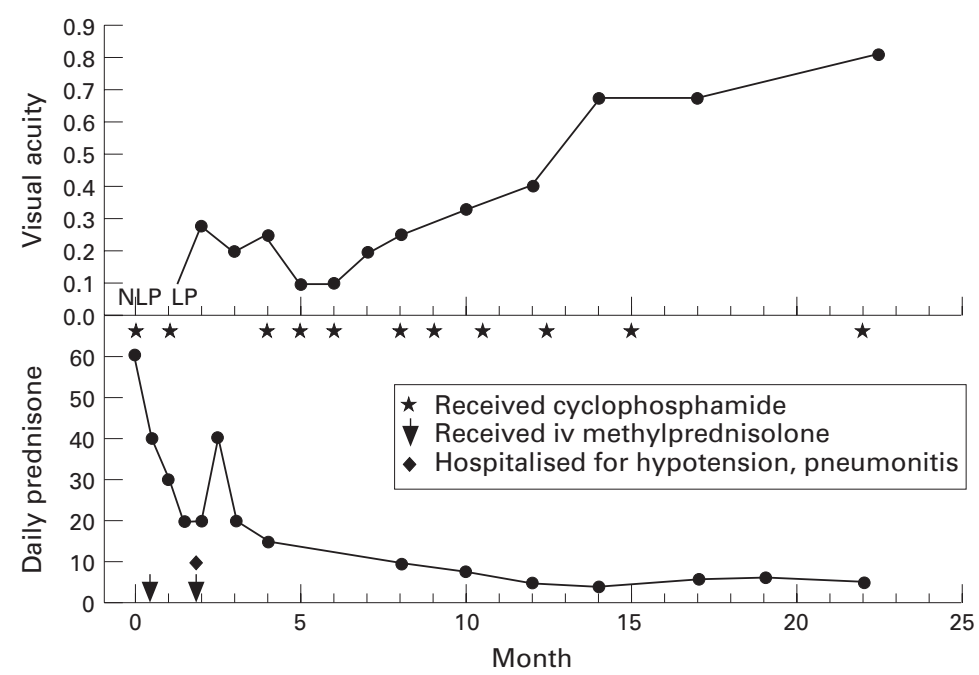

Figure 1 The visual acuity is represented as a ratio such that 20/20 would be 1 and 20/200 is represented as 0.1 . For simplicity acuities are given for the right eye only. The left eye followed a very similar course.

improvement in visual acuity was gradual. At follow up, optic nerve pallor was universally present even among those eyes which recovered excellent visual acuity.

The course for patient 1 is summarised in Figure 1. She had previously been treated with intravenous cyclophosphamide for lupus associated renal disease. This treatment was discontinued 1 year before the onset of optic neuritis. Her test for anticardiolipin antibodies was moderately positive but she had no history of thrombosis. At the onset of optic neuritis her only medication for lupus was $2 \mathrm{mg}$ of prednisone per day. Intravenous cyclophosphamide was instituted at a dose of $500 \mathrm{mg} / \mathrm{m}^{2} 13$ days after the onset of optic neuritis. The dose of cyclophosphamide was increased by $20 \%$ monthly as tolerated to an eventual maximum of $870 \mathrm{mg} / \mathrm{m}^{2}$. Her course was complicated by hospitalisation after the second treatment with cyclophosphamide. A pneumonitis developed along with hypotension and a subendocardial myocardial infarction. The lung disease may have been infectious or secondary to the lupus. Visual recovery was gradual with some improvement occurring immediately but with continued improvement for 1 year after the onset. Although acuity has recovered both optic nerves have pallor and subjectively colour vision and contrast sensitivity remain affected.

YJ, patient 2, while on corticosteroids and azathioprine, developed optic neuritis in her left eye. She had hand motion (HM) vision in her left eye and 20/20 vision in her right eye. One week later she developed acute transverse myelopathy and was treated with intravenous cyclophosphamide $\left(500 \mathrm{mg} / \mathrm{m}^{2}\right)$ immediately and again in 1 month. Her transverse myelopathy dramatically improved promptly and vision in the left eye improved to the counting fingers level and eventually to $20 / 20$. Optic neuritis in the right eye and a flare of transverse myelitis occurred after the first two treatments with cyclophosphamide. The left eye remained unchanged. Six more monthly treatments of intravenous cyclophosphamide at the same dose were given and both the optic neuritis of the right eye and the transverse myelopathy stabilised. Visual acuity in the right eye at present is $20 / 25$. Although the optic neuritis in both eyes remained stable after the initial treatment courses of cyclophosphamide, the transverse myelitis has continued to flare with cessation of therapy, and at present the patient has received a total of 28 treatments for her recurrent transverse myelopathy.

$\mathrm{FB}$, patient 3, developed acute optic neuritis with blindness in the right eye. She also developed progressive mononeuropathy multiplex despite high doses of oral corticosteroids. Intravenous cyclophosphamide $\left(500 \mathrm{mg} / \mathrm{m}^{2}\right)$ was begun and after treatment for 2 months vision in the right eye improved from light perception (LP) to $20 / 30$. The patient had a flare of mononeuropathy multiplex several years later, but this time responded to corticosteroids alone.

In addition to those patients reported here, we have evaluated four other patients with systemic lupus and optic neuropathy. One patient, ML, fits well with the three described in this report. She had severe visual loss and responded markedly to intravenous cyclophosphamide. She did not return for adequate follow up such that visual acuities and the course after the first dose of cyclophosphamide are not available. $\mathrm{KC}$ had lost vision completely in one eye secondary to optic neuritis before our evaluation. That episode had been treated by intravenous methylprednisolone. Intravenous cyclophosphamide was instituted as a corticosteroid sparing agent several months after optic neuritis had affected the second eye. At that time visual acuity had already improved to 20/25. Three more episodes over a 2 year period affected the second eye. Intravenous cyclophosphamide appeared to be effective but visual acuity was not recorded on a frequent enough basis to document this probable benefit. The patient had moved to a town 1000 miles from our practice when the fourth attack of optic neuritis occurred. This attack was treated with oral and intravenous corticosteroids and the vision did not recover beyond light perception.

Our initial report on the use of intravenous cyclophosphamide for CNS lupus also contained two other patients with optic neuropathy. Both of these patients had stable and long standing visual loss before the initiation of cyclophosphamide therapy. Their clinical response could not be evaluated with regard to recorded visual acuity nor would we anticipate that visual loss which had been stable for some time would respond.

\section{Discussion}

Optic neuropathy is a rare but well described association with autoimmune disease including giant cell arteritis, polyarteritis nodosa, ${ }^{6}$ Takayasu's arteritis, ${ }^{7}$ Churg-Strauss vasculitis, ${ }^{8}$ Behçet's disease, systemic lupus erythematosus, and relapsing polychondritis..$^{910}$ A prospective study of 550 patients with SLE noted retinopathy usually manifesting as cotton wool 
spots in $7 \% .{ }^{11}$ Only two patients had optic neuropathy. ${ }^{11}$

The most complete review of optic neuropathy in association with SLE was by Jabs et al in 1986. ${ }^{3}$ They reported improvement in four of their seven patients following treatment with corticosteroids. Their results were better than others reported in the literature which they analysed in detail. Their tabulation found that 13 of the 24 SLE patients with optic neuropathy reported by that time have final visual acuities of 20/200 or worse. ${ }^{3}$ They felt that the common underlying pathology in SLE patients with optic neuropathy (presenting as either retrobulbar neuropathy or ischaemic neuropathy) is vaso-occlusive disease in the small vessels of the optic nerves. ${ }^{3}$

Additional reports describing the association of SLE and optic neuritis have appeared since 1986. ${ }^{12-25}$ The therapeutic approach to treating optic neuritis associated with SLE has not changed in the decade since the report by Jabs and colleagues.

Our patients had unilateral or bilateral retrobulbar neuropathy occurring in the setting of well established SLE. Some of these patients also had transverse myelitis. It can be difficult to distinguish active CNS lupus from multiple sclerosis (MS) in these patients. Certainly optic neuritis and transverse myelitis are more commonly found in MS patients, but have been reported in patients with SLE. ${ }^{31213}$ There have been a few reports of the coexistence of MS with SLE as noted above, ${ }^{14}$ although some neurologists will not diagnose MS in the presence of a disease that can mimic it as well as SLE can. It may be, as Jabs et al postulate, that mild ischaemia causes demyelination and more severe ischaemia causes infarction. ${ }^{3}$ The very gradual recovery of vision in our patients with SLE is in contrast with the rapid recovery of vision characteristic of optic neuritis in association with MS.

Intravenous cyclophosphamide is effective in the treatment of lupus nephritis ${ }^{2627}$ and is gaining increasing acceptance in the treatment of neuropsychiatric lupus. ${ }^{28}$ Although intravenous cyclophosphamide is less convenient than oral and results in more nausea, it is generally considered safer and more rapidly acting than daily oral cyclophosphamide. Although optic neuritis in association with a demyelinating disease can improve spontaneously, the prognosis of optic neuritis in association with SLE has not been favourable. Our patients developed optic neuropathy in two instances while receiving appropriate immunosuppressive therapy, high doses of corticosteroids, or azathioprine.

CNS disease in SLE has many different aetiologies including vasculitis, thrombosis, infection, and antineuronal antibodies. Different aetiologies may correlate with different prognoses or suggest specific therapy. Suspected thrombosis and ischaemia with high antiphospholipid antibody titres, for example, should probably be treated with anticoagulation alone if there is no evidence of generalised lupus activity in other organ systems. For all other patients with non-infectious optic neuritis in association with SLE we believe that intravenous cyclophosphamide and corticosteroids should be the treatment of choice.

This work was supported in part by a Research to Prevent Blindness scholar award and NIH Grant EY06484.

1 McCrary JA III. Systemic associations of optic neuritis. Int Ophthalmol Clin 1991;31:163-73.

2 Beck RW, Cleary PA, Anderson MM, Jr, Keltner JL, Shults WT, Kaufman DI, et al. A randomized, controlled trial of corticosteroids in the treatment of acute optic neuritis. $N$ Engl F Med 1992;326:581-8.

3 Jabs DA, Miller NR, Newman SA, Johnson MA, Stevens MB. Optic neuropathy in systemic lupus erythematosus. Arch Ophthalmol 1986;104:564-8.

4 Neuwelt CM, Lacks S, Kaye BR, Ellman JB, Borenstein DG. Role of intravenous cyclophosphamide in the treatment of severe neuropsychiatric systemic lupus erythematosus. Am f Med 1995;98:32-41.

5 Tan EM, Cohen AS, Fries JF. The 1982 revised criteria for the classification of systemic lupus erythematosus. Arthritis Rheum 1982;25:1271-7.

6 Kimbrell OC, Wheliss JA. Polyarteritis nodosa complcated by bilateral optic neuropathy. $\mathfrak{f}$ Am Med Assoc 1967;201: by bilateral $139-40$.

7 Ito $M$. Supplementary findings on ophthalmological study of Takayasu's disease. Report II. Ischemic optic neuropathy associated with Takayasu's disease. Nippon Ganka Gakkai Zasshi 1976;80:353-60.

8 Acheson JF, Cockerell OC, Bentley CR, Sanders MD. Churg-Strauss vasculitis presenting with severe visual loss due to bilateral sequential optic neuropathy. $\mathrm{Br} \mathcal{F}$ Ophthalmol 1993;77:118-9.

9 Mamo JG, Baghdassarian A. Behcet's disease: a report of 28 cases. Arch Ophthalmol 1964;71:4-14.

10 Killian PJ, Susac J, Lawless OJ. Optic neuropathy in relapsing polychondritis. F Am Med Assoc 1978;239:49-50.

11 Stafford-Brady FJ, Urowitz MB, Gladman DD, Easterbrook M. Lupus retinopathy. Patterns, associations, and prognoM. Lupus retinopathy. Patterns, associati
sis. Arthritis Rheum 1988;31:1105-10.

12 Kenik JG, Krohn K, Kelly RB, Bierman M, Hammeke MD, Hurley JA. Transverse myelitis and optic neuritis in systemic lupus erythematosis: a case report with magnetic resonance imaging findings. Arthritis Rheum 1987;30:947-50.

13 Simeon-Aznar CP, Tolosa-Vilella C, Cuenca-Luque R, Jordana-Comajuncosa R, Ordi-Ros J, Bosch-Gil JA. Transverse myelitis in systemic lupus erythematosus: two cases with magnetic resonance imaging. Br f Rheumatol 1992;31: $555-8$.

14 Kinnunen E, Muller K, Keto P, Ketonen L, Helve T, Sepponen R. Cerebrospinal fluid and MRI findings in three patients with multiple sclerosis and systemic lupus erythematosus. Acta Neurol Scand 1993;87:356-60.

15 Ahmadieh H, Roodpeyma S, Azarmina M, Soheilian M, Sajiadi SH. Bilateral simultaneous optic neuritis in childhood systemic lupus erythematosus. A case report. $\mathcal{f}$ Neuro-Ophthalmol 1994;14:84-6.

16 Oppenheimer S, Hoffbrand BI. Optic neuritis and myelopathy in systemic lupus erythematosus. Can $\mathcal{F}$ Neurol Sci 1986;13:129-32.

17 Fleet WS, Watson RT. Autoimmune optic neuritis: a potentially treatable form of visual loss. Ann Ophthalmol 1986;18:144-6.

18 Tamoaka A, Murayama S, Sonoh M, Matsumura K, Sakuta $M$. [Two cases of retrobulbar neuritis and transverse myelopathy as the initial symptoms suggestive of systemic lupus erythematosus (SLE) - case report and review of literature]. Rinsho Shinkeigaku [Clinical Neurology] 1986;26: 483-9.

19 Prokaeva TB, Alekberova ZS. [Optic neuritis in systemic lupus erythematosus (personal case and review of the literature)] [Russian]. Revmatologiia 1985;4:40-4.

20 Smith CA. Optic neuritis in systemic lupus erythematosus. [Letter] f Rheum 1985;12:190.

21 Cherednichenko VM, Zhabotinskaia NV, Bakul IV. [A case of optic neuritis in a child with systemic lupus erythematosus.] Oftalmologicheskii Zhurnal 1990;2:123-4.

22 Ichiki S, Ohfu M, Niimi K, Hayashida K, Ishii T, Oda T. [A case of systemic lupus erythematosus associated with mencase of systemic lupus erythematosus associated with men1989;29:126-33.

23 Drosos AA, Petris CA, Petroutsos GM, Moutsopoulos HM. Unusual eye manifestations in systemic lupus erythematosus patients. Clin Rheumatol 1989;8:49-53.

24 Lahoz RC, Arribas LJR, Monereo AA, Arnalich FF. [Optic neuritis and systemic lupus erythematosus (letter)]. Revista Clinica Espanola 1989;184:216.

25 Deutsch TA, Corwin HL. Lupus optic neuritis with negative serology. Ann Ophthalmol 1988;20:383-4.

26 McCune WJ, Golbus J, Zeldes W, Bohlke P, Dunne R, Fox DA. Clinical and immunologic effects of monthly adminisration of intravenous cyclophosphamide in severe system lupus erythematosus. N Engl F Med 1988;318:1423-31.

27 Austin HA, Klippel JH, Balow JE, LeRiche NGH, Steinberg AD, Plotz PH, et al. Therapy of lupus nephritis. Controlled trial of prednisone and cytotoxic drugs. $N$ Engl $f \mathrm{Med}$ trial of predniso

28 Neuwelt CM, Kaye BR, Babich JF. Role of intravenous cyclophosphamide (IV-CYC) in the treatment of severe neuropsy-
chiatric lupus erythematosus (NPSLE) 30 month followup-1993-June, 1995. Arthritis Rheum 1995;38:346. 